\title{
Turizm ve Rekreasyon Alanında Eğitim Veren Kurumlarda Güvenlik ve Bir Özdeğerlendirme Kontrol Listesi Önerisi
}

\author{
Özkan TÜTÜNCÜ - İpek AYDIN \\ Dokuz Eylül Üniversitesi \\ Spor Bilimleri Fakültesi
}

\section{GíRiş}

Dünyada önemle üzerinde durulan konulardan biri şiddet içermeyen güvenli okulların oluşturulmasıdır. Güvenli okullar olmadan, öğretmenler etkili bir şekilde öğretme ve öğrenciler öğrenme sürecini gerçekleştirememektedir. Okul güvenliği, öğrencinin okuldaki refahını tehdit edici herhangi bir durumu ifade etmektedir. Bu tür bir durum öğrencinin kendisinden kaynaklanabildiği gibi başkaları tarafından da kaynaklanabilir (Duke 2002). Bu kapsamda okul güvenliği, öğretmenlerin güvenli bir ortamda eğitim ve öğretim hayatlarına devam edebilecekleri, öğrencilerin samimi, tehlike ve tehditlerden uzak, eğitim ve öğretimi cesaretlendiren bir ortamı ifade etmektedir. Güvenli okullar oluşturmak, okuldan fazlasını içeren kapsayıcı ve işbirliğine dayalı bir süreçtir (Stephens 1994). Bu kapsamda, okul güvenliği, öğretmenler, öğrenciler, ebeveynler, emniyet-güvenlik çalışanları, psikolojik danışmanlık ve rehberlik uzmanları, politikacılar, akademisyenler ve iş dünyası gibi birçok paydaşı etkileyen ve bu paydaşlardan etkilenen bir kavramdır.

Ülkemizde turizm ve rekreasyon alanında eğitim veren birçok kurum bulunmaktadır. Eğitim kurumlarının kalite ve güvenliğinin artırılması, kurum liderleri ve yöneticileri açısından birincil öncelikte olmakla birlikte, bunu gerçekleştirmelerine olanak tanıyacak rehber özdeğerlendirme araçları sınırlıdır. Akademik hayattaki öğretim elemanlarının çalışmalarında daha ziyade teorik alana yönelmeleri, pratik çıktıları olan çalışmaların azlığı, teori ile pratik arasındaki uyumsuzluklar, eğitim kurumlarımızın gelişimini olumsuz yönde etkilemektedir. Buradan hareketle bu çalışmanın temel amacı turizm ve rekreasyon alanında eğitim veren kurumların güvenliğine yönelik bir özdeğerlendirme kontrol listesi oluşturmak ve önermektir. Bununla birlikte önerilen listenin her türlü eğitim kurumunda kullanılmas1 olasidir.

\section{Okul Güvenliği ve Güvenlik Kontrolü}

Okul güvenliği, öğrencinin okula giderken ve okulda geçirdiği süre boyunca okuldaki varlıklarının, sosyo-duygusal iyilik durumunun riske atılmadığı bir ortam anlamına gelmektedir (Astor vd. 2009). Okul güvenliğinin geliştirilmesine yönelik gerçekleştirilen çalışmalar dahilinde bazı yaklaşımlar ve modeller üzerinde durulmaktadır. Bunlardan en temeli Biyoekolojik modeldir (Bronfenbrenner 2005). Bu model, okullarda güvenlikle ilgili yaşanabilecek olumsuzlukları önleyici ve bu olumsuzluklara müdahale ederken içinde bulunulan toplumun davranışlarının neler olduğu ve okul güvenliğini nasıl etkilediği ile ilgilenmektedir. Bu modele göre içinde bulunulan çevre birey üzerinde büyük bir etkiye sahiptir ve bireyin, kişilerle, kurumlarla olan iletişimini ve etkileşimini etkilemektedir.

Morrison ve diğerleri (1994), güvenli okul ve eğitim ortamının birtakım özellikleri olduğunu vurgulamışlardır. Bunlar; okul geliştirme planında açık bir şekilde tanımlanmış hedefler, bu hedeflere yönelik ilerlemenin izlenmesi ve geribildirim, öğrencilerin akademik başarıları, olumlu davranış beklentileri, öğrencinin okula bağlılığ 1 ve süreçlere katılımı, ebeveyn ve toplumun sürece katılmasıdır. 
Folks (2008), okul güvenliğinin kontrolü amaciyla değerlendirme kriterlerinin oluşturulabileceğini ifade etmiştir. Bu değerlendirme kriterlerini altı temel başlık altında incelemiştir;

Öğrencilerin okul güvenliğiyle ilgili hazır bulunuşlukları: Öğrencilerin okul güvenliği ile ilgili bilgilendirilmesi, onların sürece dahil edilmesi, güvenlikle ilgili problemleri iletebilecekleri kişi veya birimlerin bulunmasını ifade etmektedir.

Okul binasına erişim koşulları: Okul güvenliği kapsamında erişim kontrolünün sağlanması önemlidir (Dorn vd. 2004). Bu kontrol tutarlı bir şekilde uygulanan politika ve prosedürler çerçevesinden izlenmeli ve değerlendirilmelidir. Kontrolün sağlanması amaciyla teknolojik cihaz ve ekipmanlara ihtiyaç duyulabilir; ancak bu kurulumun yüksek maliyeti, uygulamaya engel teşkil edebilir (Garcia 2003).

Acil durum planları: Okul yetkilileri acil durum karşısında görev ve sorumluluk paylaşımı yapmalıdır. Bu planlar sistematik bir şekilde güncellenmelidir. Acil durum planı ve karşılaşılabilecek acil durumlar için hazırlık eğitimi verilmelidir.

Okul binasının güvenliği: Okul girişleri, istenmeyen kişilerin okula girişinin engellenmesi, öğrencilerin diş tehditlerden uzak tutulabilmesi, gerektiğinde öğrencilerin hızlıca bir araya toparlanabilmesi, sığınağın olması gibi özellikler okul binasının güvenliği kapsamında değerlendirilebilir (Schneider 2005).

Öğrencilerin birbirleriyle olan iletişimi: Okulların, öğrencilerin birbirlerine karşı saygılı, nazik ve özverili olmak gibi davranışlar sergilemeleri konusunda teşvik edici bir pozisyonda olmalarını ifade etmektedir. Öğrencilerin birbirlerinin sağlıklarını tehdit edici bir ortam oluşmasının önlenmesi gerekmektedir. Öğrencilerin sosyal ve duygusal refahının düşük olduğu okul ortamında fiziksel şiddet olaylarının daha yaygın olduğu görülmektedir (Bear vd. 2006).

Denetimlerin gerçekleştirilmesi: Okul güvenliğini arttırmanın en etkili ve ucuz yolu, okul binasi genelinde okul yetkililerinin yerleştirilmesidir (Sprague ve Walker 2005).

\section{Okul Güvenliği ve Okul İklimi}

Genel olarak okul güvenliği, okul iklimi algısı ile ilişkilendirilmiştir (Bradshaw vd. 2014; Berg ve Cornell 2016). Olumlu okul iklimi ve güvenlik duyguları, yüksek akademik başarı ve diğer uyum sağlama ölçütleri ile ilişkilendirilmiştir (Berkowitz vd. 2017). Etkili bir okul-öğrenme iklimi, öğretmen-öğrenci ilişkilerini geliştirmenin yanı sıra, öğrencilerin başarı için olanaklarının geliştirilmesini de içermektedir. Greene (2005) okul ikliminin okul şiddeti ve önlenmesinin doğası ve kapsamı üzerinde büyük bir etkisi olduğunu vurgulamıştır.

Birçok araştırmacı, okul iklimi, okula bağlılık ve kişisel güvenlik duygularının okul güvenliğini anlamadaki en önemli değişkenlerden bazıları olduğunu düşünmektedir (Karcher 2004; Whitlock 2006). Öğrencilerin bireysel özelliklerine göre okul güvenliğine yönelik bazı çalışmalar gerçekleştirilmiştir (Booren ve Handy 2009; Varjas vd. 2009). Astor ve diğerleri (2010) tarafından gerçekleştirilen çalışmada, farklı bakış açılarındaki farklılıkları anlamak, okul şiddeti ve güvenlik konularını için iyi tasarlanan ve uygulanan programların oluşturulmasına katkı sağlayabileceği vurgulanmıştır. Öğrencilerin algıları, güvenli okul ortamlarının en iyi şekilde nasıl oluşturulacağını anlamak için önemli olabilir. Örneğin, Phillips (2007) gerçekleştirdiği çalışmada erkekler tarafından uygulanan şiddetin toplumsal bir sorun olduğunu ve bu nedenle şiddetin erkek olmanın bir parçası olarak öğrencilerin benimsediğini belirtmiştir. Bu nedenle, sadece okulda bulunan öğretmen ve öğrencilerin algılarının değil, toplum davranışlarının da okul güvenliği kapsamında değerlendirilmesi büyük önem taşımaktadır.

\section{Okul Güvenliği ve Paydaşlar}

Tüm öğretim kademesindeki okulların, okul güvenliği konusunu önemsemeleri önemlidir ve bunu yapmanın temel aşaması, okul içindeki bileşenlerin farklı algılara sahip olup olmadığını anlamaktır. Öğretmenler, öğrenciler, okulun diğer çalışanlarının okul güvenliği ile ilgili görüşlerini belirlemek gerekmektedir, ancak öğrencilerin okulda güvenlik algılarına etki eden faktörlerin neler olduğu çok net değildir (Lopez vd. 
2017). Öğrenciler okulun büyük bir bölümünü oluşturduğundan, öğrencilerin okul güvenliği, iklimi ve güvenlik stratejileri hakkındaki algılarını yakından incelemek gerekmektedir (Booren vd. 2011).

Genel olarak algılar değerlendirilirken öğrenci ve öğretmen bakış açısı önemlidir. Okul ortamı ile ilgili sorunları değerlendirirken öğrencilerin algılarının, öğretmenlerin algılarına göre gerçeği daha iyi temsil ettiği belirlenmiştir (Stone ve Isaacs 2002). Bir diğer çalışmada da okul iklimi ile ilgili olarak öğrencilerin, öğretmenlerden daha düşük puan verdikleri ve öğretmenlerin okul iklimini öğrencilerden \%40 daha iyi derecelendirdikleri sonucuna ulaşılmıştır (Skiba vd. 2006). Bu da okul güvenliği ile ilgili algıları değerlendirirken tüm yönleriyle ele alma gerekliliğini ortaya koymaktadır. Öğrencilerin ve tüm okul personelinin ortak bir amaç için birlikte çalıştıkları ve şiddet içeren davranışları tanımak ve ele almak için oluşturdukları bir program ile öğrencilerin, okul ortamlarını daha güvenli algıladıklarını göstermiştir (Oswald vd. 2005). Öğrencinin de süreçlere katılımı okula olan bağlılığını artırabilir. Bu da okula bağlı öğrencilerin olumsuz sosyal normlardan uzak durmaları ve okul kurallarına uymalarını daha muhtemel hale getirebilir (Welsh 2003).

\section{YÖNTEM}

$\mathrm{Bu}$ çalışmanın amacı turizm ve rekreasyon alanında eğitim veren kurumların güvenliğine yönelik bir özdeğerlendirme aracı-kontrol listesi önerisi oluşturmaktır. Çalışma okul güvenliği ile ilgili belirlenmiş özdeğerlendirme araç ve kontrol listelerinin taranması ve incelenmesine bağlı bir derleme olarak ele alınabilir. Bu bağlamda okul güvenliği ile ilgili yapılmış özdeğerlendirme araçları ve kontrol listeleri arama motorları üzerinden araştırılmış ve incelemeye tabii tutulmuştur. Arama motorlarında ilk taramada incelemeye değer 96 çalışma saptanmıştır. Ancak konuyla ilgili birbirinden bağımsız şekilde temel unsurları içinde bulunduran ve sistematik bir yaklaşıma sahip bulunan 13 özgün çalışma (Kaynakçada erişim tarihi 21.10.2019 olarak verilen tüm çalışmalar) detaylı bir şekilde incelemeye alınmıştır.
İkincil veriler kapsamında yapılmış olan bu çalışmaların gözden geçirilmesi, değerlendirilmesi, yorumlanması ve senteze yönelik derlenmesi bu makalenin temel yöntemini oluşturmaktadır. Çalışmanın kaynak taraması, alan incelemeleri ve özdeğerlendirme kontrol listesi önerisi Georgia Devlet Üniversitesi, J. Mack Robinson İşletme Fakültesi, Uluslararası Ticaret Eğitimi ve Araştırmaları Merkezi'nde gerçekleştirilmiştir. Çalışma konusu ve çıktısı her ne kadar turizm ve rekreasyon alanında eğitim veren kurumlar özelinde gözükse de çalışma aslında tüm eğitim kurumları ve okullarına uyarlanabilir. Bu nedenle çalışma içinde önerilen özdeğerlendirme kontrol listesi sadece turizm ve rekreasyon alanında eğitim veren kurumlar için değil aynı zamanda diğer eğitim kurumları için de uygulanabilir niteliktedir.

\section{BULGULAR}

Saptanan on üç çalışmada yapılan tarama ve incelemelerde, eğitim kurumlarının uygulamada güvenliği ondokuz ana başlık ve üç önemli süreç üzerinden değerlendirebilecekleri saptanmıştır. Bu başlıklar ve süreçler yukarıda alan yazın değerlendirilmesinde sunulan çalışmalar ile uyumlu, onları kapsayan daha geniş bir çerçevededir. Kontrol listesinin son kısmı eğitim kurumlar1nın hangi düzeyde olduğunu değerlendiren üç süreçten oluşmaktadır. Bu süreçlerin ilk düzeyi önleme, ikinci düzeyi yanıt verme-eyleme geçme ve son düzeyi erken uyarı sistemi-farkında olmaktan oluşmaktadır. Bu düzeylere yönelik detaylar asıl kontrol listesinde bulunmaktadır. Bu kapsamda okul güvenliğine yönelik ana başlıklar ve örnek maddeleri aşağıdaki özdeğerlendirme kontrol listesi önerisinde sunulmaktadır.

\section{Eğitim Kurumlarında Güvenlik Özdeğerlendirme Kontrol Listesi}

\section{Acil Durum Planlaması}

1. Çalışanlara risk analizi, acil durum yönetimi, iş sağlığı ve güvenliği ile ilgili eğitim verilmelidir.

2. Acil durum yönetim modeli dahilinde, meydana gelebilecek her türlü tehlikeye yönelik önle- 
me, hazırlıklı olma, müdahale etme ve kurtarma faaliyetleri planlanmalidir.

3. Planlar düzenle olarak gözden geçirilmeli ve güncellenmelidir (Yılda en az bir kez).

4. Planlar özel gereksinimi olan öğrencileri kapsayacak şekilde ele alınmalıdır.

5. İç alanlar engelli bireyleri göz önüne alarak, mevzuata uygun bir şekilde (TS 9111) yapılandırılmalıdır.

\section{Güvenlik Politikaları}

1. Gerektiğinde emniyet kuvvetlerinin aşağıdaki durumlara müdahale edebilmelidir.

a. Zorbalik

b. Taciz ve şiddet

c. Kriz yönetimi

d. Dayak atma

e.Öğrenci disiplini

2. Okul riskli davranışlarda bulunan öğrencilere yönelik, onlara yardımcı olabilecek bir öğrenci takımı oluşturabilir.

\section{Uygulamalı Eğitim ve Tatbikatlar}

1. Her bir öğretim yılında her bir okul binasında aşağıdaki uygulamalı eğitim ve tatbikatlar gerçekleştirilmelidir.

a. Her yıl en az iki kez deprem eğitimi ve tatbikatı (Eğitim yılının başladığı ilk on beş gün içinde ilk deprem eğitimi ve tatbikatının verilmesi) yapilmalıdir.

b. Her yıl en az iki kez yangın eğitimi ve tatbikatı yapilmalıdır.

c. Her yıl en az iki kez güvenli kilit pozisyonuna (uçaklardaki acil durum pozisyonu gibi) geçilmesi eğitim ve tatbikatı yapılmalıdır.

d. Kötü hava koşulları eğitimi (Okulların bulunduğu bölgeye bağlı olarak) verilmelidir.

\section{Okul Binasının Güvenliği ve Erişimi}

1. Güvenli giriş ve çıkışı sağlayacak güvenlik politikası, sistem ve uygulamaları vardır.

2. Her binaya tek noktadan güvenli giriş ve çıkış yapılmaktadir.
3. Belirlenmiş giriş noktaları, binaya erişimler açısından izlenmekte ve kontrol edilmektedir.

4. Okul çalışanları veya görevli personel, öğrencilerin giriş ve çıkışlarını güvenlik açısından izlemektedir.

5. Okulun ana girişi, müdür odasından rahatlıkla izlenebilmektedir.

\section{Giris Kartlar, Anahtarlar ve Teslimatlar}

1. Giriş kartlarını ve anahtarları (Ana- anahtar ve yedek anahtarlar) denetim altında tutan bir sistem kurulmalıdır.

2. Giriş kartları ve anahtarlar yedekleri ile birlikte, yıllık olarak kontrol edilmektedir.

3. Acil durumlarda (Yangin, deprem vb.) okula girişlerin hızlı bir şekilde yapılmasını sağlayacak, yetkilendirilmiş ulaşılabilir bir anahtar sistemi olmalıdır.

4. Tüm çalışanlar fotoğraflı bir kimlik kartı taşımalıdır.

5. Çalışanların işten ayrılması durumunda kimliklerini, kurumlarına teslim etmeleri gerekmektedir.

\section{Ziyaretçiler}

1. Tüm girişlerde ziyaretçilerin uymaları gereken politika ve prosedürler, görülebilir şekilde ilan edilmelidir.

2. Ziyaretçiler aşağıdaki kuralları yerine getirmelidirler:

a. Fotoğraflı kimliklerini göstermeli ve kimliklerinin saptanmasına olanak tanıyacak kıyafet giymelidirler.

b. Giriş ve çıkışlar kayıt altına alınmalıdır.

3. Giriş-çıkışların kayıt altına alınabileceği uygun bir donanım ve personelin sağlanması gerekmektedir. (Karşılama masası, telefon, telsiz vb.)

4. Ziyaretçilerin kimlikleri, diğer ziyaretçilerin ulaşamayacağı bir yerde muhafaza edilmelidir.

5. Gerekli durumlarda ziyaretçilere okul içinde refakat edilebilmelidir. 


\section{Çalışanların Ĕ̆itimi}

1. Çalışanlar aşağıdaki konularda eğitim almalıdirlar.

a. Tehdit değerlendirmesi

b. Tüm gerekli tatbikat ve tahliye eğitimleri

c. Şüpheli ve olağandışı faaliyetler hakkında farkındalık

d. Çevredeki düzensizlikler hakkında farkındalığın sağlanması (Şüpheli araçlar vb.)

e. Şüpheli hareketlerin veya paketlerin incelenmesi

f. Şüpheli telefon veya terör faaliyetleri karşısında alınabilecek tutum ve davranışlar

2. Acil durum müdahale ekipleri ilkyardım konusunda sertifikalı eğitim almalıdır.

3. Kalp krizi gibi olaylara defiblatör ile müdahale edebilecek ekip üyeleri eğitim almalıdır.

4. Okul acil durum ekiplerinin planlı ve plansız tatbikat ve uygulamalar gerçekleştirmeli ve yeterliliklerinin kontrolü sağlanmalıdır.

\section{Fiziksel Koşullar}

1. Okul iyi bir karşılama ortamına sahip olmalıdır.

2. Öğrencilerin okulu sevmesi, sahiplenmesi ve gurur duymasını sağlamak için eserleri ve başarıları okul koridorlarında yeterince sergilenmelidir.

3. Okul ortamı ve çevresi öğrencilerin yapacağı faaliyetlere olanak tanıyıp, teşvik etmeli ve katılımını sağlamalıdır.

4. Fiziksel ortamdaki aksaklıklar hızlı bir şekilde giderilmelidir.

5. Fiziksel ortamların 1sis1, makul (22-26 derece) düzeyde olmalıdır.

\section{Iletișim}

\section{Okul İletişim Sistemi}

1. Okul yönetimi tüm paydaşlarla çift yönlü (tek yönlü değil) bir iletişim oluşturmalıdır.

2. Acil durum alarm sistemine entegre veya bağımsız çalışan, karbon monoksit uyarı sistemi olmalıdır.
3. Altı ayda bir alarm sisteminin kontrol edilmesi ve sağlıklı çalıştı̆̆ından emin olmak gerekmektedir.

4. Tüm katlarda acil durum alarm sistemi oluşturulmalı ve sınıflarda acil durumlarda aranacak olan acil servis 112, itfaiye 110, polis 155 ile ilgili bilgilendirmeleri sağlanmalıdır.

5. Çalışanlarla gerçekçi ve uygulanabilir güvenlik talimatları oluşturulmalı ve devreye sokulmalıdır.

\section{Dış Çevre}

1. Yollarda okulun bulunduğunu net bir şekilde belirten işaretlemeler olmalıdır.

2. İşaretlemeler mevzuatta belirtilen renklerde ve standartlarda olmalıdır.

3. Okulun etrafı mevzuata uygun bir şekilde çitle çevrilmelidir.

4. Okul genel giriş kapılarının mesai saatleri d1şında güvenliği sağlanmalıdır.

5. Okul çevresinin güvenlik tehditlerinden (geçiş engelleri, enkaz vb. olmaması) temiz olması sağlanmalıdır.

\section{Servis Araçları ve Park Yerleri}

1. Servis araçlarının öğrenci alma yerleri, müdüriyet odalarından veya çalışanlar tarafından görülebilir olmalıdır.

2. Servis araçlarının acil durumlara müdahaleyi engellemesi önlenmelidir.

3. Otopark alanları yeterli şekilde aydınlatılmalidir.

4. Mevzuata uygun sayıda otopark alanı olmalıdır.

5. Yangın musluklarının önlerine araçların park etmesi engellenmelidir.

\section{Dinlence-Rekreasyon ve Oyun Alanları}

1. Dinlence ve oyun alanları çit ile çevrili olmalidir.

2. Oyun alanlarına taşıtların girmesi engellenmelidir.

3. Cankurtaran ve acil durum araçlarının dinlen-

Cilt $30 \bullet$ Sayı $3 \bullet$ Güz 2019 
ce ve oyun alanlarına ulaşımı kısıtlanmamalıdir.

4. Varsa tribünler sağlam olmalı ve bakımları yapilmalidir.

5. Oyun alanlarının ve ekipmanlarının yeterliliği ve güvenliğinde:

a. Bu alanlarda çukurların hiçbir şekilde olmamasına dikkat edilmelidir.

b. Direklerde keskin köşe ve kenarlar olmamalıdır.

c. Her türlü donanım güvenli olmalıdır. Keskin uçlu kancalar hiçbir yerde olmamalıdır.

d. Yükseltili alanlarda, rampalarda, tribünlerde ve benzerlerinde, tutunma yerleri, korkuluk ve tırabzanlar olmalıdır.

e. Boşluklar (örneğin korkulukların yükseklikleri veya merdiven basamakları araları) risksiz olmalıdır.

\section{İç Alanlar ve Sınıflar}

1. Merdivenler ve merdiven boşlukları yeterli ve düzgün bir şekilde aydınlatılmalıdır.

2. Merdivenlerde yürümeyi zorlaştıracak engeller ve zemin kaygan olmamalıdır.

3. Merdiven tırabzanları mevzuata uygun yükseklikte ve sağlam olmalıdır.

4. Koridorlar:

a. Yeterli ve düzgün bir şekilde aydınlatılmalıdır.

b. Temiz olmalı, yürümeyi zorlaştıracak engeller olmamalıdır.

c. Yeterli alarm düğmesi ve uyarı sistemi olmalıdır.

d. Camlar temiz ve pencereler kullanışlı olmalıdır.

e. Duvarlar temiz olmalıdir.

f. Acil çıkışlar rahatlıkla görülebilir olmalıdır.

g. Lambaların kırılmalara karşı, güvenliği sağlanmalıdır.

h. Kör noktalar parabolik aynalara ile görülebilir hale getirilmelidir.

5. Kapılar sağlam ve çalışan bir kilit sistemine sahip olmalıdır.

Kantin, Kafeterya ve Mutfaklar

1. Bu alanların sorumlu bir yöneticisi olmalıdır.
2. Yeterli ve düzgün bir şekilde aydınlatılmalıdır.

3. Varsa soğuk hava deposunun kapısı içeriden açlabilmeli ve içinde alarm sistemi olmalıdır.

4. Bu alanların fiziksel koşulları öğrencilerin hızlı, güvenli ve rahat bir şekilde giriş çıkışlarına olanak tanımalıdir.

5. Kantin ve kafeteryalarda sadece okul yönteminin izin verdiği, sağlıklı ürünler satılmalıdır.

\section{Spor Salonları ve Yüzme Havuzları}

1. Aydınlatma lambaları ve pencereler, koruma altına alınmış olmalı, salondaki kişilerin güvenliğini riske atmamalıdır.

2. Defibratörler beden eğitiminin yapıldığ 1 alanlarda konumlandırılmalıdır.

3. Salonlarda kullanılan matlar ve diğer malzemelerin düzenli kontrolleri yapılmalı, sağlıklı olduklarından emin olunmalı ve gerekli bakımları sağlanmalıdır.

4. Malzemeler düzgün bir şekilde muhafaza edilmeli ve korunmalıdır.

5. Acil durum çıkışlarının önünde hiçbir engelleme olmamalı ve bu çıkışlar net bir şekilde işaretlendirilmiş olmalıdır.

Özel Alanlar (Tiyatro Salonları, Bilim ve Sanat Alanları, Atölyeler, Laboratuvarlar)

1. Acil durum prosedürleri bu alanlar için belirlenmiş ve tanımlı olmalıdır.

2. Acil durumlarda öğrenciler bu alanların tahliyesi konusunda bilinçlendirilmiş olmalıdır.

3. Acil durum çıkışlarının önünde hiçbir engelleme olmamalı ve bu çıkışlar net bir şekilde işaretlendirilmiş olmalıdır.

4. Bu alanlarda kullanılacak ek teçhizat ve malzemelerin (kablo vb.), güvenliği tehdit etmemesi sağlanmalıdır.

5. Bu alanların sahne arkasındaki düzenlemeler, acil durum çıkışlarını engellememelidir.

\section{Tuvaletler}

1. Tuvaletlerde sağlıklı çalışan havalandırma sistemi olmalıdir.

2. Tuvaletlerin düzenli temizliği, sanitasyon ve hijyeni sağlanmalıdır. 
3. Tuvaletlerde sürekli sıvı sabun olması sağlanmalıdir.

4. Tuvaletlerde el kurutmaya yönelik, tercihen kâğıt havlu veya kurutma sistemleri olmalıdır.

5. Tuvaletlerde sürekli tuvalet kâğıdı olmalıdır.

\section{Güvenlik Kameraları}

1. Güvenlik kameraları okulun dışına uygun bir şekilde yerleştirilmelidir.

2. Güvenlik kameralarının mümkün olan en geniş alanı kapsaması sağlanmalıdır.

3. Güvenlik kameraları okul içine uygun bir şekilde yerleştirilmelidir.

4. Güvenlik kameraları güvenlik personeli veya yetkilendirilmiş bir kişi tarafından mevzuata uygun düzenli izlenmelidir.

5. Kayıtları saklama süresi belirlenmelidir ve kayıtlar güvence altına alınmalıdır.

Kontrol listesi toplamda 22 sayfadan oluşmaktadir. Listede yer alan her ifadenin gerçekleşme durumları, bu ifadelerin yanında yer alan diğer sütün içinde değerlendirilmektedir. Makale ve köşe yazıları formatından dolayı, burada bu kontrol listesinin sadece belirli bir kısmı ve örnek olabilecek maddeleri sunulmaktadır. Listenin asıl formatı yukarıdaki gibi değildir. Kontrol listesinin aslı, ozkan.tutuncu@deu.edu.tr adresinden istenilebileceği gibi, Anatolia Turizm Araştırmaları Dergisi internet bağlantısından da indirilebilir.

\section{SONUÇ}

Ülkemizde iş sağlığı ve güvenliği kapsamında eğitim kurumlarında risk analizlerinin yapılması gerekmektedir. Bununla birlikte eğitim kurumlarının güvenliklerini, kendileri tarafından değerlendirebilecekleri rehber listelerin yeterli olmadığı saptanmaktadır. Buradan hareketle bu eksikliği kapatabilmek adına bu araştırma alandaki diğer çalışmaların taranmasına bağlı bir derleme olarak, yurtdışında halen uygulanmakta olan ve özgünlüğü saptanan toplam 13 okul güvenliği özdeğerlendirme kontrol listesi bazında ele alınmıştır. Buradan hareketle yukarıda bir kısmı verilen ancak kullanım formatındaki tamamına yazarlarından (ozkan.tutuncu@deu.edu.tr) veya Anatolia Turizm Araştırmaları Dergisi'nden ulaşılabilecek özdeğerlendirme aracı, eğitim kurumları ve okulların güvenliklerini artırmaya yarayacak bazı ipuçlarını vermektedir. Bu liste sadece üzerine odaklanılması gereken alanları ortaya koymaktadır. Bu listelerin veya rehberlik verecek standartların oluşturulmaları elbette önemlidir ancak kâğıt üstünde kalan yüzeysel çalışmaların, alanın kalite ve güvenliğine katkı sağlamaktan çok bu alanın içinin boşaltılmasına neden olabileceği unutulmamalıdır. Önemli olan kurum liderleri ve çalışanlarının bu konuya eğilerek, örgüt iklimi ve kültüründe, güvenlik kültürünün iyileştirilmesine ve geliştirilmesi yönelik faaliyetleri gerçekleştirmeleri ve içselleştirilmeleridir.

Burada önerilen kontrol listesi taranan çalışmaların her birinin ortak önemli bulduğu veya her birinin ele almadığı ancak bu derleme çalışmay1 yapan yazarlar tarafından önemli olduğu düşünülen ayrı parçaları ele alan eserler bazında ve yazarların kendi düşüncelerinden hareketle, oluşturulmuştur. Bu nedenle çalışma içindeki bazı maddeler her kurum için geçerli olmayacağ 1 gibi her kurumun kendi özelliklerinden kaynaklanan durumlardan yeni maddelerin listelere eklenmesi gerekebilir. Bundan sonraki çalışmaların bu alanda yapılmış diğer çalışmaları göz önünde bulundurarak, çalışma maddelerini ve önerilerini geliştirmesi yerinde olacaktır.

Teşekkür: Bu çalışmanın kaynak taraması, alan incelemeleri ve özdeğerlendirme kontrol listesi önerisi Georgia Devlet Üniversitesi, J. Mack Robinson İşletme Fakültesi, Uluslararası Ticaret Eğitimi ve Araştırmaları Merkezi'nde gerçekleştirilmiştir. Çalışmanın birinci yazarına bu olanakları sağlayan Merkez Müdürü Prof. Dr. Tamer Çavuşgil'e teşekkürlerimizi sunarız.

\section{KAYNAKÇA}

4J Eugene School District (t.y.). School/Department Safety Inspection Checklist, http://www.4j.lane.edu/files/hr/4J_ HR_RM_safety_inspection_checklist.pdf, Erişim tarihi: 21.10.2019

Astor, R. A., Meyer, H. A., Benbenishty, R., Marachi, R. ve Rosemond, M. (2005). School Safety Interventions: Best Practices and Programs, Children \& Schools, 27: 17-32. 
Astor, R., Benbenishty, R. ve Estrada, J. (2009). School Violence and Theoretically Typical Schools: The Principal's Centrality in Orchestrating Safe Schools, American Educational Research Journal, 46(2): 423-461.

Berkowitz, R., Moore, H., Astor, R. ve Benbenishty, R. (2017). A Research Synthesis of The Associations between Socioeconomic Background, Inequality, School Climate, and Academic Achievement, Review of Educational Research, 87(2): 425-469

Booren, L. M. ve Handy, D. J. (2009). Students' Perceptions of the Importance of School Safety Strategies: An Introduction to the IPSS Survey, Journal of School Violence, 8: $233-250$.

Booren, L. M., Handy, D. J. ve Power, T.G. (2011). Examining Perceptions of School Safety Strategies, School Climate, and Violence, Youth Violence and Juvenile Justice, 9(2): 171-187.

Bradshaw, C. P., Waasdorp, T. E., Debnam, K. J. ve Johnson, S. L. (2014). Measuring School Climate in High Schools: A Focus on Safety, Engagement, and The Environment, Journal of School Health, 84(9): 593-604.

Bronfenbrenner, U. (Editör). (2005). Making Human Beings Human: Bioecological Perspectives on Human Development. Thousands Oaks, CA: Sage.

CJCP. (t.y.). The School Safety Diagnostic Tool, http://www. cjcp.org.za/uploads/2/7/8/4/27845461/safety_audit_and_ checklist.docx, Erişim tarihi: 21.10.2019

Delaware Department of Education (2002). School Safety Audit Guidelines, https://www.doe.k12.de.us/cms/lib/ DE01922744/Centricity/Domain/473/SchoolsafetyAudit2002.doc, Erişim tarihi: 21.10.2019

Dorn, M., Thomas, G. Wong, M. ve Shepherd, S. (2004). Janes: Safe Schools Planning Guide for all Hazards (1st Ed.). Coulsdon, UK: Sentinel House.

Duke, D. L. (2002). Creating Safe Schools for All Children. Boston: Allyn \& Bacon.

EGfL (2014). Schools Annual Health \& Safety \& Welfare Inspection Checklist, https://www.egfl.org.uk/facilities/buildings-and-assets/premises-logbook, Erişim tarihi: 21.10.2019

Folks, K. (2008). School-Safety Preparedness: A Qualitative Study Of Principals' Perceptions of Using A School-Safety Checklist. (Basılmamış Doktora Tezi). Indiana: Purdue University.

Garcia, C. A. (2003). School Safety Technology in America, Criminal Justice Policy Review, 14(1): 30-54

Georgia Department of Education (t.y.). School Safety Assessment, https://www.gadoe.org/schoolsafetyclimate/Documents/School\%20Safety\%20Assessment.pdf, Erişim tarihi: 21.10 .2019

HSE (2011). Health and Safety Checklist for Classrooms, www.hse.gov.uk/risk/classroom-checklist.htm, Erişim tarihi: 21.10.2019

Karcher, M. J. (2004). Connectedness and School Violence: A Framework for Developmental Interventions.İçinde E. R. Gerler (Editörler), Handbook of School Violence (ss. 7-40). Binghamton, NY: Haworth Press.
López, V., Torres-Vallejos, J., Villalobos-Parada, B., Gilreath, T. D., Ascorra, P., Bilbao, M., Morales, M. ve Carrasco, C. (2017). School and Community Factors Involved in Chilean Students'perception of School Safety, Psychology in the Schools, 54 (9): 991-1003.

Minke, K.M., ve Bear, G.G. (2000). Preventing School Problems-Promoting School Success: Strategies and Programs that Work. Bethesda, MD: National Association of School Psychologists. Mahwah. N.J: Lawrence Erlbaum Associates, Inc.

Minnesota Department of Public Safety. (t.y.). Safe School Self-Assessment Checklist, https://dps.mn.gov/divisions/ hsem/mn-school-safety-center/Documents/School\%20Safety\%20Checklist.pdf, Erişim tarihi: 21.10.2019

Morrison, G. M., Furlong, M. J. ve Morrison, R. L. (1994). From School Violence to School Safety: Reframing the Issue For School Psychologists, School Psychology Review, 23:236-256.

NEMLEC (t.y.). School Safety Audit Review Checklist, http:// www.starstoolkit.org/prevent/school-safety-audit-reviewchecklist, Erişim tarihi: 21.10.2019

New Hampshire Department of Education Division of Program Support (2018). School Facility Self-Assessment Checklist, https://www.education.nh.gov/program/school_approval/documents/school-facility-self-assess-checklist_ jan8-18.doc, Erişim tarihi: 21.10.2019

New Jersey Department of Education (2011). School Safety \& Security Plan Review Checklist, https://www.state.nj.us/ education/schools/security/req/checklist.pdf, Erişim tarihi: 21.10.2019

Oswald, K., Safran, S. ve Johanson, G. (2005). Preventing safer Trouble: Making Schools Places Using Positive Behavior Supports, Education $\mathcal{E}$ Treatment of Children, 28: 265-278.

Phillips, D. A. (2007). Punking and Bullying: Strategies in Middle School, High School, and Beyond, Journal of Interpersonal Violence, 22: 158-178.

Schneider, T. (2005). Essential Questions to Raise During A Building Project, School Administrator, 62(5): 39-39.

Seton. School Safety Checklist, https://www.seton.net.au/media/setonschool/School_Safety_Checklist.pdf, Erişim tarihi: 21.10.2019

Shaddock, A., Giorcelli, L., Smith S. (2007). Students with Disabilities in Mainstream Classrooms, https://www.inclusive.tki.org.nz/assets/inclusive-education/resource-documents/InclusiveClassroom TeacherResourceFinal1.pdf, Erişim tarihi: 21.10.2019

Skiba, R., Simmons, A. B., Peterson, R. ve Forde, S. (2006). The SRS Safe School Survey: A Broader Perspective on School Violence Prevention. İçinde S. R. Jimerson \& M. J. Furlong (Editörler.), Handbook of School Violence And School Safety: From Research to Practice (157-170). Mahwah, NJ: Lawrence Erlbaum.

Sprague, J.R. ve Walker, H.M. (2005.) Safe and Healthy Schools. New York: Guilford

Stephens, R. D. (1994). Planning for Safer and Better Schools: School Violence Prevention and Intervention Strategies, School Psychology Review, 23(2): 204-215. 
Stone, C. ve Isaacs, M. L. (2002). Involving Students in violence Prevention: Anonymous Reporting and the Need to Promote and Protest Confidences, NASSP Bulletin, 86: 54-65.

Varjas, K., Henrich, C. C. ve Meyers, J. (2009). Urban Middle School Students' Perceptions of Bullying, Cyberbullying, And School Safety, Journal of School Violence, 8: 159-176.

Vermont Department of Education (2005). School Safety Review Checklist, http://www.healthyvermonters.info/hp/ act125/envisionplan.shtml, Erişim tarihi: 21.10.2019
Welsh, W. N. (2003). Individual and Institutional Predictors of School Disorde, Youth Violence and Juvenile Justice, 1: 346-368.

Özkan TÜTÜNCÜ, Prof. Dr., Dokuz Eylül Üniversitesi, Spor Bilimleri Fakültesi, Rekreasyon Bölümü, 35330 İzmir.

E-posta: ozkan.tutuncu@deu.edu.tr

ORCID: 0000-0002-2482-0893

Ipek AYDIN, Öğretim Görevlisi, Dokuz Eylül Üniversitesi, Spor Bilimleri Fakültesi, Rekreasyon Bölümü, 35330 İzmir.

E-posta: ipek.aydin@deu.edu.tr

ORCID: 0000-0002-9355-5712 